\title{
"MULTIPLICATIVE ERROR MODEL ON NORTHERN HEMISPHERIC VOLCANIC SULFATE AND EUROPEAN TEMPERATURE ANOMALIES,
}

\author{
Nazario Tartaglione* \\ NORCE Norwegian Research Centre, Bjerknes Centre for Climate Research, Bergen, Norway
}

\section{Article history}

Received July 7, 2018; accepted March 15, 2019.

Subject classification:

Multiplicative and additive errors; Linear models; Volcanic sulfate; Surface air temperature; Climate.

\begin{abstract}
It is generally accepted that volcanic eruptions may have a climatic impact involving overall cooling of the troposphere, as the sulfur injected into the stratosphere is transformed into sulfate. However, it is intrinsically difficulty to distinguish this impact because of natural climate variability. In this paper, we look for a relationship between sulfate in the Northern Hemisphere (NH) and European temperature during the last 500 years using two independent data sets: stratospheric sulfate retrieved from ice cores and European seasonally and annually averaged temperature. Relationships between temperature and sulfate are obtained as a function of the season (summer and winter) and location (tropics vs extra-tropics) one and two years after the sulfate record year. After one year, we always find a negative correlation in the winter for both tropical and extra-tropical eruptions. A correlation value of -0.56 is obtained for the relationship between sulfate and annually averaged temperature anomalies after one year, and a linear regression predicts a cooling of $1{ }^{\circ} \mathrm{C}$ for an eruption of $100 \mathrm{Tg}$ of sulfate, an amount similar to that estimated to have been emitted by the Laki eruption in 1783.

The variability of the cooling effect after one year is evaluated by introducing a multiplicative error model for sulfate that accounts for systematic as well as random errors in retrieved sulfate. To evaluate the impact of sulfate uncertainties on the regression slope, a resampling approach with $10^{4}$ simulations is applied. Results indicate that when uncertainties in sulfate are introduced, the variability of cooling is in the order of several $10^{-3}{ }^{\circ} \mathrm{C} / \mathrm{Tg}$. Temperature anomaly uncertainties impact slope uncertainty but have little influence on slope variability.
\end{abstract}

\section{INTRODUCTION}

Volcanic eruptions are one of the main natural forcings of the Earth's climatic system. Eruptions can inject large or small amounts of sulfur in the atmosphere [Hofmann, 1987; McCormick et al., 1995], in the form of $\mathrm{SO}_{2}$ and occasionally of $\mathrm{H}_{2} \mathrm{~S}$ [Rampino and Self, 1984]. Sulfate in the stratosphere, obtained by the chemical transformation of sulfur injected by volcanoes into $\mathrm{H}_{2} \mathrm{SO}_{4}$ aerosols, has been recognized as one of more im- portant factors influencing volcano-climate interactions [Toon and Pollack, 1980; Robock and Mao, 1992, 1995; Camuffo and Enzi, 1995; Briffa et al., 1998; Robock, 2000; Dunn, 2004; Langmann, 2014]. Although volcanic sulfate represents only a fraction of the total sulfate present in the atmosphere, the strength of volcanic explosions and the height of volcanic eruption clouds contribute to the injection of sulfate into upper levels of the troposphere and the stratosphere where it can persist for more than one year [Robock and Mao, 
1995; Sear et al., 1987; Crowley and Kim, 1999; Hegerl et al., 2003; Jones et al., 2004; Fischer et al., 2007; Esper et al., 2013].

The injection of large amounts of sulfur can have an important impact on temperature and, hence, on human activities. While it seems undoubtable that large volcanic eruptions can lead to a decrease in surface temperature [Sadler and Grattan, 1999], the estimation of how many degrees the atmosphere cools owing to a given amount of volcanic sulfate is problematic. There is uncertainty with the total mass of sulfur emitted [Arfeuille et al. 2014; Gautier et al., 2016], especially in the stratosphere, and how and where the majority of the sulfur transforms into sulfate [Baroni et al., 2008]. The size of volcanic particles also plays a fundamental role in radiative forcing, as well as atmospheric residence times, and, consequently, it affects surface temperature [Timmreck et al, 2009; Timmreck, 2012]. For single eruptions, the magnitude of the climatic signal can be masked by climate noise unless the eruption is large enough that the impact on climate can be unambiguously distinguished [Swingedouw, 2017]. Hence, the magnitude of climatic response to volcanic eruptions is still debated. Real data are sparse, and uncertainties with sulfate estimates can affect the model response, as volcano forcing is based on observations [Ammann et al., 2003].

Although an intrinsic difficulty to depict the temperature response to volcanic eruptions exists [Bradley, 1988; Mass and Portman, 1989], there have been attempts in the past to estimate the cooling effect in quantitative terms. Devine et al., [1984] found that the mean surface cooling associated with five eruptions appeared to vary linearly with the cube root of the estimated minimum mass of sulfur released by the eruptions. Mass and Portman [1989], analyzed nine years of eruptions, and, among those considered, five were classified as intense. Most of the eruptions analyzed were located in the NH or in tropical regions. The eruptions they used were relatively recent, occurring from 1883 onwards, and thus large eruptions like Tambora and Laki were not included. They found a mean cooling effect of approximately $0.3^{\circ} \mathrm{C}$ and claimed that eruptions do not play an important role in the Earth's climate.

Reanalyzing the data from Devine et al. [1984] and Mass and Portman [1989], using a regressive model, we find a relationship between stratospheric sulfate mass, as estimated from ice cores, and surface temperature anomalies. We even investigate the role of the season and of the eruption type. We propose applying a bootstrap to evaluate variability and uncertainty for the slope that relates sulfate and temperature. We de- fine variability as the result of having different mean values of the slope, while uncertainty is the error bar associated with each average slope value.

We present a multiplicative model for the (unknown) sulfate error and, with these errors, we re-calculate the slope under different sets of parameters that define the error model. Some hypotheses on temperature uncertainty are discussed, and we demonstrate that sulfate uncertainty contributes to the majority of slope variability, while temperature uncertainty has little impact.

\section{DESCRIPTION OF DATA}

The amount of volcanic sulfate is a difficult quantity to measure, and there is debate on how much sulfate is obtained after each eruption. If nowadays (since 1978), we can measure sulfur emissions with satellites, we cannot say the same for past eruptions when satellite data were not available, and the amount of sulfur injected during past eruptions is, therefore, necessarily associated with larger uncertainties [Scaillet et al., 2003; Textor et al., 2005].

\subsection{SULFATE DATA SET}

This data set consists of the mass of sulfate released by volcanic eruptions from both hemispheres from the year 500 to the year 2000 . However, for our study, only data from the $\mathrm{NH}$ and the period from 1500-2000 were considered because the temperature dataset covers that period (Figure 1). The original data set was built by analyzing 54 polar ice cores, and the sulfate released was obtained with a calibration factor that relates sulfate

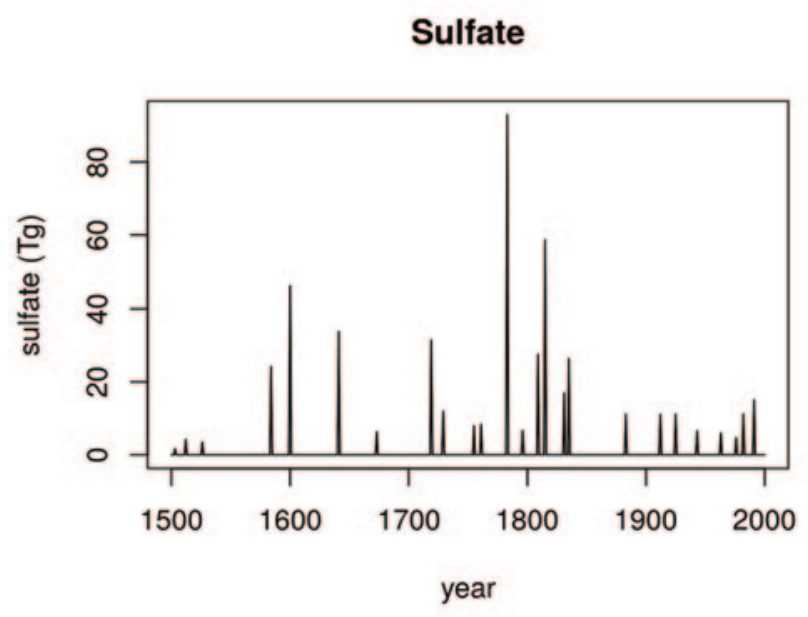

FIGURE 1. The sulfate (in Tg) as retrieved by Gao et al. [2008] for the Northern Hemisphere. 


\begin{tabular}{|c|c|c|c|c|}
\hline Year & Volcano & Latitude & $\begin{array}{l}\text { Estimate of sulfate injected } \\
\text { in northern hemisphere }(\mathrm{Tg})\end{array}$ & Reference \\
\hline 1503 & $\begin{array}{l}\text { St. Helen } 1500 \\
\text { Atitlan, Guatemala } 1504\end{array}$ & $\begin{array}{l}46.2 \mathrm{~N} \\
14.6 \mathrm{~N}\end{array}$ & 1.72 & BJ92 AM03 \\
\hline 1512 & $\begin{array}{l}\text { Hekla } 1510 \\
\text { Sangeang Api } \\
\text { Gunungapi Wetar }\end{array}$ & $\begin{array}{l}64.0 \mathrm{~N} \\
8.2 \mathrm{~S} \\
6.6 \mathrm{~S}\end{array}$ & 4.24 & BJ92 AM03 AM03 \\
\hline 1526 & Arenal 1525 & $10.5 \mathrm{~N}$ & 3.54 & BJ92 \\
\hline 1584 & $\begin{array}{l}\text { Billy Mitchell } 1580 \\
\text { Kelut, Java } 1586\end{array}$ & $\begin{array}{l}6.1 \mathrm{~S} \\
8.0 \mathrm{~S}\end{array}$ & 24.23 & $\begin{array}{l}\text { BR98 } \\
\text { BJ92 BR98 AM03 }\end{array}$ \\
\hline 1600 & $\begin{array}{l}\text { Huaynaputina } \\
\text { Quilotoa }\end{array}$ & $\begin{array}{l}16.6 \mathrm{~S} \\
0.9 \mathrm{~N}\end{array}$ & 46.08 & $\begin{array}{l}\text { BR98 AM03 } \\
\text { BJ92 }\end{array}$ \\
\hline 1641 & $\begin{array}{l}\text { Komaga } 1640 \\
\text { Parker }\end{array}$ & $\begin{array}{l}42.1 \mathrm{~N} \\
6.1 \mathrm{~S}\end{array}$ & 33.81 & BR98 BR98 AM03 \\
\hline 1673 & $\begin{array}{l}\text { San Salvador } 1671 \\
\text { Gamkanora }\end{array}$ & $\begin{array}{l}13.7 \mathrm{~N} \\
1.4 \mathrm{~N}\end{array}$ & 6.34 & $\begin{array}{l}\text { BJ92 } \\
\text { BJ92 BR98 AM03 }\end{array}$ \\
\hline 1719 & Wudalianchi & $48.8 \mathrm{~N}$ & 31.48 & Feng and Whitford-Stark, 1986 \\
\hline 1729 & Krafla & $65.7 \mathrm{~N}$ & 12.02 & Brandsdottir et al., 1997 \\
\hline 1755 & Katla & $63.0 \mathrm{~N}$ & 7.96 & BJ92 \\
\hline 1761 & Mount Vesuvius & $44.6 \mathrm{~N}$ & 8.41 & Rosi et al., 1993 \\
\hline 1783 & $\begin{array}{l}\text { Laki } \\
\text { Asama }\end{array}$ & $\begin{array}{l}64.0 \mathrm{~N} \\
36.4 \mathrm{~N}\end{array}$ & 92.96 & $\begin{array}{l}\text { BJ92 } \\
\text { BJ92 }\end{array}$ \\
\hline 1796 & $\begin{array}{l}\text { Pogrommi } 1795 \\
\text { Amak Bogoslov }\end{array}$ & $\begin{array}{l}54.6 \mathrm{~N} \\
55.4 \mathrm{~N} \\
53.9 \mathrm{~N}\end{array}$ & 6.69 & $\begin{array}{l}\text { BJ92 } \\
\text { Plummer, } 1898 \\
\text { Plummer, } 1898\end{array}$ \\
\hline 1809 & Unknown & & 27.56 & \\
\hline 1815 & $\begin{array}{l}\text { Mayon } 1814 \\
\text { Tambora }\end{array}$ & $\begin{array}{l}11.3 \mathrm{~N} \\
8.2 \mathrm{~S}\end{array}$ & 58.69 & $\begin{array}{l}\text { BJ92 } \\
\text { BJ92 BR98 AM03 }\end{array}$ \\
\hline 1831 & $\begin{array}{l}\text { Unimak } 1830 \\
\text { Mount St. Helens } \\
\text { Babuyan Claro }\end{array}$ & $\begin{array}{l}54.8 \mathrm{~N} \\
46.2 \mathrm{~N} \\
19.5 \mathrm{~N}\end{array}$ & 16.97 & $\begin{array}{l}\text { Plummer, } 1898 \\
\text { Plummer, } 1898 \\
\text { AM03 }\end{array}$ \\
\hline 1835 & Cosiguima & $13.0 \mathrm{~N}$ & 26.36 & BJ92 BR98 AM03 \\
\hline 1883 & $\begin{array}{l}\text { Krakatau } \\
\text { Augustine } \\
\text { Nasu } 1881\end{array}$ & $\begin{array}{l}6.1 \mathrm{~S} \\
59.4 \mathrm{~N} 34.1\end{array}$ & 11.16 & $\begin{array}{l}\text { BJ92 BR98 } \\
\text { BJ92 } \\
\text { BJ92 }\end{array}$ \\
\hline 1912 & $\begin{array}{l}\text { Katmai } \\
\text { Novarupta } \\
\text { Lolobau } 1911 \\
\text { Taal } 1911\end{array}$ & $\begin{array}{l}58.0 \mathrm{~N} \\
58.0 \mathrm{~N} \\
4.9 \mathrm{~S} \\
14.0 \mathrm{~N}\end{array}$ & 11.04 & $\begin{array}{l}\text { BJ92 } \\
\text { BR98 } \\
\text { BJ92 AM03 } \\
\text { AM03 }\end{array}$ \\
\hline 1925 & $\begin{array}{l}\text { Raikoke } 1924 \\
\text { Santorini }\end{array}$ & $\begin{array}{l}48.3 \mathrm{~N} 3 \\
6.5 \mathrm{~N}\end{array}$ & 11.15 & $\begin{array}{l}\text { BJ92 } \\
\text { Washington, } 1926\end{array}$ \\
\hline 1943 & Parìcutin & $19.5 \mathrm{~N}$ & 6.61 & Pioli et al., 2008 \\
\hline 1963 & Agung & $6 \mathrm{~S}$ & 7.61 & BJ92 AM03 \\
\hline 1976 & $\begin{array}{l}\text { Augustine } \\
\text { Fuego } 1974\end{array}$ & $\begin{array}{l}59.4 \mathrm{~N} \\
14.5 \mathrm{~N}\end{array}$ & 4.72 & $\begin{array}{l}\text { BJ92 } \\
\text { BJ92 }\end{array}$ \\
\hline 1982 & El Chicòn & $17.4 \mathrm{~N}$ & 11.20 & AM03 \\
\hline 1991 & Pinatubo & $15.1 \mathrm{~N}$ & 15.05 & BR98 AM03 \\
\hline
\end{tabular}

TABLE 1. A selection of volcanic events over the last 500 years using data from Gao et al. [2008]. The first column is the year of the eruption, as estimated by ice core dataset. The second column shows the volcano associated with the eruption (figures close to the name are other estimates of the eruption year found in the literature). The third column shows the latitude of the volcano (approximated to the first decimal digit). The forth column shows the sulfate retrieved (in $\mathrm{Tg}$ ) by the ice cores for that year [after Gao et al., 2008]. In the last column lists the authors that reported the eruption. In particular, the works of Ammann and Naveau [2003], Bradley and Jones [1992] and Briffa et al. [1998], identified in the table as AM03, BJ92, and BR98, respectively, were used. 
depositions measured in the ice cores to the total mass of stratospheric aerosol [Gao et al., 2008]. Hemispheric calibration factors were determined to allow for comparisons between polar regions for ice core sulphate depositions (in $\mathrm{kg} \mathrm{km}^{-2}$ ) and the total mass of stratospheric aerosol formed after each eruption (in kg).

As we limited our analysis to a period of 500 years in the $\mathrm{NH}$, only 22 out of the 25 events of Figure 1 were considered, with the first three events excluded. Not all the eruptions considered in the present work are from $\mathrm{NH}$ volcanoes. As can be seen in Table 1, some of the volcanic eruptions that led to the injection of sulfate in the NH occurred in tropical regions. Most of the events reported in Table 1 were taken from Bradley and Jones [1992], Briffa et al. [1998], Ammann and Naveau [2003] and others (see references in Table 1). The event associated with the highest value of sulfate occurred in 1783, corresponding to the eruption of the Laki volcano, in Iceland [Highwood and Stevenson, 2003]. It should be noted that the eruption of the Asama volcano, located in Japan, was also reported in 1783 [Zielinski et al., 1994].

The problem with these kinds of data is the uncertainties associated with them. As observed by Arfeuille et al. [2014] there are uncertainties both with calibrations and with the partitioning of volcanic sulfate between the Northern and Southern Hemispheres in the case of eruptions of tropical volcanoes. Arfeuille at al. [2014] discusses a few cases where the calibration led to discrepancies between sulfate computed by ice cores and other observations. Possible errors may be present in dating as suggested by Baillie and McAneney [2015], who found discrepancies between tree-ring and ice chronologies. We note that a problem might be related to the proximity of volcanoes to the polar re- gions. Certainly, this might be the case with Laki, for example. GAO et al. [2008] argued that the total uncertainty of their data is about $50 \%$ caused by different volcanic signal extraction criteria, sulfate deposition owing to the transport simulations, and the choice of calibration factor.

\subsection{TEMPERATURE DATA SET}

The temperature dataset used in this article is that presented in Luterbacher et al. [2004]. These data are obtained by multiproxy reconstructions of monthly and seasonal surface temperature fields for Europe back to 1500 by using the instruments described by Mitchell and Jones [2005] and Hansen et al. [2001]. This data set was obtained with multiproxy reconstructions of monthly and seasonal surface temperature fields for Europe back to 1500 using the instruments described in Xoplaki et al. [2005] to evaluate variability, trends, uncertainties, and extreme changes of reconstructed and observed European spring and autumn temperature back to 1500 .

While uncertainties cannot be estimated with precision, we know that they decrease with time, and, for the sake of simplicity, we suppose a random uncertainty following a normal distribution having a standard deviation of $1^{\circ} \mathrm{C}$. To know how temperature uncertainty affects the slope value, we performed a Monte Carlo simulation by varying the temperature uncertainty and keeping almost as a constant the sulfate uncertainty (a small uncertainty was still associated with it).

The temperature used is shown in Figure 2. All the computations are made using the temperature anomaly with respect to the 30-year moving average (the red line in Figure 2).

\section{European mean temperature}

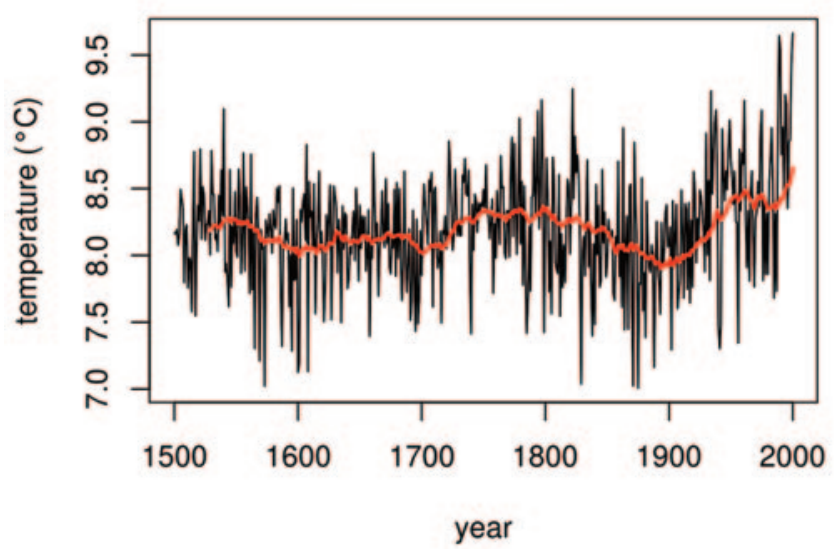

FIGURE 2. Temperature averaged on Europe (after Luterbacher et al. [2004]) and 30 years moving average (red line). 


\section{STATISTICAL ANALYSIS AND ROLE OF ERUP- TION TYPE AND SEASON}

We analyzed the relationship between European temperature anomalies and stratospheric sulfate by means of a simple linear regression that accounted for the annually averaged temperature and all the eruptions from the data set (subsection 3.1), and also for season and eruption type (tropical or extra-tropical; subsection 3.2). The role of the eruption magnitude on the linear relationship is also investigated in subsection 3.3.

\subsection{LINEAR REGRESSION ANALYSIS WITH TEMPER- ATURE ANOMALIES}

We start our statistical analysis with a linear regression between northern hemispheric sulfate emissions and European mean temperatures.

As it is known that aerosols injected by volcanoes have a short time influence on climate, we analyzed the correlation between sulfate emissions and the temperature from one year after the eruption. One year after the eruption event, the correlation between sulfate and temperature is moderately strong, with a Pearson correlation between temperature and sulfate mass of 0.56 . However, there are a few outliers corresponding to emissions larger than $40 \mathrm{Tg}$ (Figure 3).

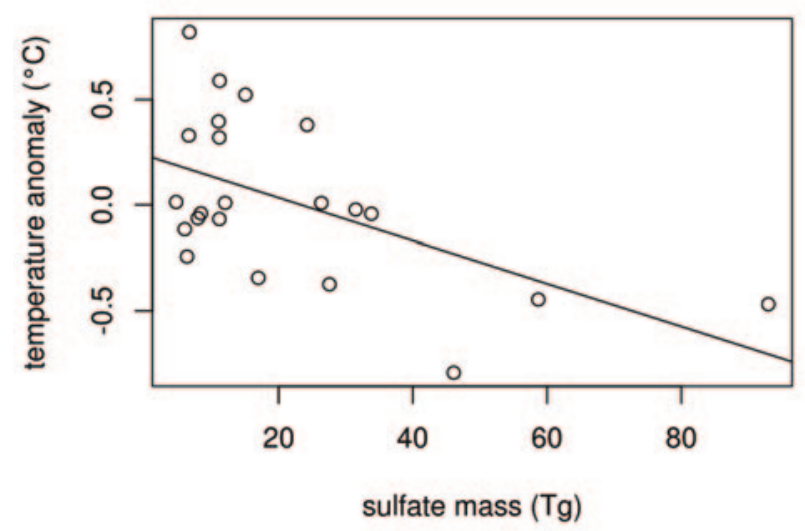

FIGURE 3. The relationship between sulfate mass (in $\mathrm{Tg}$ ) and temperature anomaly $\left(\right.$ in ${ }^{\circ} \mathrm{C}$ ) obtained using the "lm" function from the R statistical package [R Development Core Team, 2008].

The linear model predicted a cooling of $10 \times 10^{-3}{ }^{\circ} \mathrm{C}$ per Tg of sulfate injected into the atmosphere; thus large or multiple eruptions that inject $100 \mathrm{Tg}$ of sulfate would cause an average cooling of $1{ }^{\circ} \mathrm{C}$ in Europe. We verified all the conditions for applying a linear model; namely linearity, nearly normal residuals, and constant variability of data or residuals. Within the framework of linear regression, we used the Student's t-test to evaluate the strength of evidence that the slope that relates sulfate mass with temperature cooling is significantly different from zero at a 5\% significance level.

Moreover, we performed a test of significance by using a nonparametric bootstrap technique. The null hypothesis $\left(\mathrm{H}_{0}\right)$ is that the values of correlation and slope found in the linear model occurred by chance. If $\mathrm{H}_{0}$ is false, then the alternative hypothesis is true, and the correlation and the slope values should fall in the tail of the distributions of correlations and slopes obtained by resampling the temperature data. We randomly selected 22 values of temperature from the temperature data set and randomly assigned them to the northern hemispheric sulfate observed between the years 1500 and 2000. For each sample, we computed the parameters of the linear model. This procedure was repeated 2000 times, and statistics of the results were analyzed in light of the values of the correlation and the slope found previously. Figure 4 demonstrates how the observed value of the slope found is in the tail of the distribution. The horizontal line is the fifth percentile, and the vertical line is the slope found with the original data. The slope of $-10 \times 10^{-3}{ }^{\circ} \mathrm{C} / \mathrm{Tg}$ was therefore found to be significant, as there is a less than $5 \%$ probability of finding this result by chance. The probability of finding a correlation of -0.56 by chance is also less than $5 \%$. Therefore, we found that the relationship between stratospheric sulfate and temperature was significant.

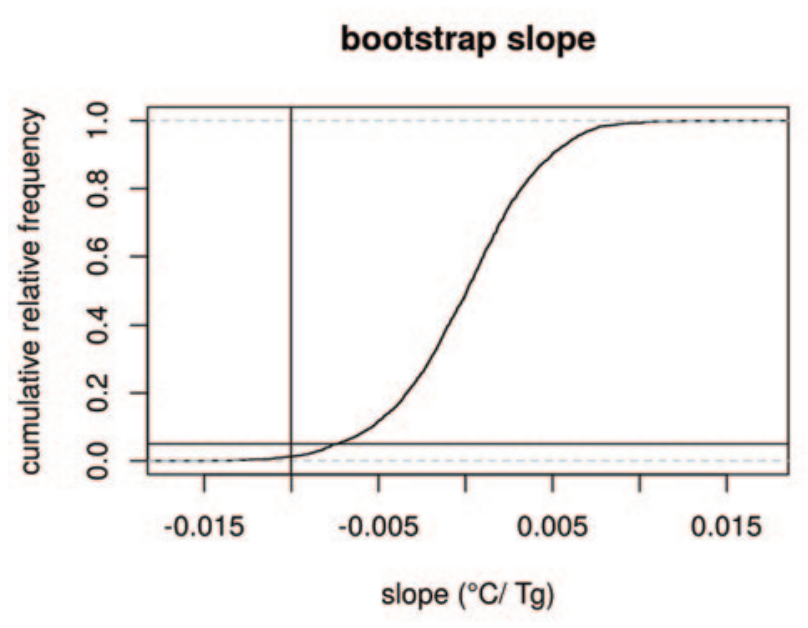

FIGURE 4. Cumulative frequency of the slopes obtained by a bootstrap of data. The vertical line represents the slope of the original data (see Fig. 3). The horizontal line indicates the $5^{\text {th }}$ percentile. 
As eruption effects are supposed to last for up to two years, we looked for a relationship between sulfate mass and temperature two years after the eruptions. This correlation after two years was found to be lower than that obtained after one year, with a Pearson correlation of only -0.28 . The linear regression, after two years, gives a slope of about $-5 \times 10^{-3}{ }^{\circ} \mathrm{C} / \mathrm{Tg}$, suggesting a cooling effect on the average temperature value between the first and second year. After three years, the correlation was completely lost. Thus, from these data, there is evidence that the impact of an eruption is important primarily during the first year after the eruption. Observations and model simulations generally demonstrate a significant cooling only in the first two or three years after the eruption; afterwards, a marginally significant temperature increase reflects the relaxation to an equilibrium climate state without volcanic forcing [Hegler et al., 2003; Merlis et al., 2014].

\subsection{ACCOUNTING FOR SEASONS AND LOCATIONS}

The analysis described above was replicated on extra-tropical and tropical eruptions. Among the 22 eruptions selected, we classified 11 as tropical and 11 as extra-tropical. The analysis was applied for two different seasons, namely summer and winter, and for one year and two years after the eruption year. Table 2 shows the results obtained. When we used all the eruptions, we obtained after one year since the eruption, a strong cooling during the winter and a slight increase of the temperature anomaly. No statistical significance was found during the summer. After two years, there is not enough statistical significance to claim that eruptions have an influence on climate.

Looking at the type of eruption, we noticed, even after two years, that extra-tropical eruptions caused a cooling in Europe during the wintertime, although the cooling was statistically significant for only one year after the eruption. For the summer, the relationship found was not statistically significant whether we considered all the eruptions, or we limited our analysis to the two eruption sub-groups. While the tropical eruptions are equal in number to the extratropical eruptions, they produced temperature anomalies that could barely be classified as statistically significant. However, when we lowered the limit of the statistical significance to $90 \%$, the warming observed in Europe after two years from the tropical eruptions became statistically significant. In general, after one year a cooling effect was observed. However we want to underline how statistical significance is important to discriminate whether a correlation actually exists.
In general, the impact of volcanic eruptions on the Earth's climate is controversial. It is quite well known that tropical eruptions may induce winter warming and a cooling effect on summer at higher latitudes [Fischer et al., 2007] although the mechanism is not perfectly clear. It has been suggested that atmospheric aerosols induce and strengthen Arctic oscillation or North Atlantic oscillation [Shindell et al., 2004; Fischer et al. 2007]; [Wunderlich and Mitchell, 2017]. For example, even the observations and simulations of tropical eruptions having the same magnitude as the Pinatubo eruption exhibit a possible warming effect at higher latitudes [Robock and Mao, 1992; Merlis et al. 2014]. There is also evidence of a winter warming at the higher latitudes of the northern hemisphere associated with tropical eruptions [Robock and Mao, 1992; Luterbacher et al., 2004; Fischer et al., 2007] This relationship is difficult to measure, as different eruptions can occur in the same year in both the tropical and extra-tropical regions.

\subsection{THE ROLE OF ERUPTION MAGNITUDE}

There are three events with estimated emissions of more than $40 \mathrm{Tg}$ of sulfate in the data set. In 1783, the eruptions of Laki and Asama were recorded, but the stratospheric mass loading of sulfate for the Asana eruption was estimated to be $3.5 \mathrm{Tg}$ [Zielinski et al., 1994], a fraction of that injected by Laki. Thus, the major impact on European climate should be because of the Laki eruption [Zielinski et al., 1994; Witham and Oppenheimer, 2004]. The Tambora and Huaynaputina eruptions were tropical eruptions, and they are two out of the three eruptions with the highest sulfate levels. One year after these three eruptions, average temperatures were lower than the mean, both in summer and winter. A winter warming effect did occur for the two major tropical eruptions, but only two years after the eruption.

To test whether the slope we found is still valid even without outliers, we removed the three eruptions with stratospheric sulfate larger than $40 \mathrm{Tg}$, and we found that the slope of the linear regression is $8 \times 10^{-3}{ }^{\circ} \mathrm{C} / \mathrm{Tg}$. However, this result is not significant when applying a t-test and the bootstrap technique adopted previously, so the most intense eruptions, in reality, give us more information than all other simulations together. Although these three sets of data are important in determining a significant slope for the linear regression that describes the relationship between stratospheric sulfate and temperature, we can say that the linear model is robust as the three eruptions are real and not spurious data. Moreover, the value of $8 \times 10^{-3}{ }^{\circ} \mathrm{C} / \mathrm{Tg}$ is 


\begin{tabular}{lccccccc} 
& \multicolumn{3}{c}{ Extra-tropical } & \multicolumn{2}{c}{ Tropical } & \multicolumn{2}{c}{ All } \\
& +1 & +2 & +1 & +2 & +1 & +2 \\
WINTER & -20.9 & -5.0 & -16.1 & +22.7 & -20.0 & +4.7 \\
SUMMER & +1.0 & -9.3 & -10.2 & +9.4 & -2.8 & -3.5 \\
ANNUAL & -8.3 & -10.3 & -13.1 & +7.9 & -10.1 & -4.4 \\
\hline
\end{tabular}

TABLE 1. Slopes $\left({ }^{\circ} \mathrm{C} / \mathrm{Tg}\right) \times 10^{-3}$ found by distinguishing extra-tropical and tropical events after one and two years after the eruptions. The figures in bold are significant at 95\% based on a student's t-test.

still a high value. As for a large eruption of $1000 \mathrm{Tg}$, the model, without outliers, would predict a cooling of $8{ }^{\circ} \mathrm{C}$.

A technique to estimate the slope uncertainty is the jackknife procedure [Wilks, 2006] for which, given a sample of $\mathrm{n}$ independent observations, the slope is recomputed $n$ times, removing a different pair of the data (sulfate yield and temperature) each time leaving only the other 21 couples. Once we compute n slopes we can have a statistic for the slope and the correlations. With 22 slopes computed with the jackknife method, the mean and median values are surprising close to that found with 21 couples of values, the mean value of the slope is still $-10 \times 10^{-3}{ }^{\circ} \mathrm{C} / \mathrm{Tg}$. The jackknife methods give also an indication of possible uncertainty to associate with the mean value. The standard deviation is $1 \times 10^{-3}$ ${ }^{\circ} \mathrm{C} / \mathrm{Tg}$, so taking twice the standard deviation as measure of the uncertainty associated with the determination of the slope we can estimate a cooling, by means the jackknife procedure, of $(10 \pm 2) \times 10^{-3}{ }^{\circ} \mathrm{C} / \mathrm{Tg}$.

\section{DEALING WITH SULFATE AND TEMPERA- TURE UNCERTAINTIES}

In this section, we introduce a multiplicative error model that has been generally concluded to be more appropriate for quantifying errors for positive value variables, such as precipitation [Tartaglione, 2010].

The estimation of the true value of sulfate is modeled with the following equation

$S_{t}=\mathrm{M}(\mu, \sigma) S_{o} e^{r}$

in which $\mathrm{S}_{\mathrm{o}}$ is the sulfate estimated from ice cores, $\mathrm{S}_{\mathrm{t}}$ is the supposed true sulfate value, and $\mathrm{M}$ is related to the multiplicative error that we can associate with systematic errors in determining the true sulfate actually present in the atmosphere. This error has an average factor $\mu$, and a standard deviation $\sigma$; $r$ is related to the random error, and it represents the standard deviation of the Gaussian process associated with these random errors whose mean is supposed to be zero. Although not frequently used in geoscience, Eq. 1 can be found in error precipitation estimation [Tartaglione, 2010; Tian et al., 2013] and it is often used in other disciplines such as biostatistics [Baskerville, 1972] and econometry [Brownlees et al., 2011].

Despite technological improvements, sources of error in $\mathrm{SO}_{2}$ flux measurements are still present even when direct measurements are performed [Tamburello et al., 2011].

The first approach is to suppose that there is not a multiplicative error, but only a random Gaussian error, with mean value equal o zero, whose standard deviation is set from 0.01 to 0.5 .

In such a case Equation 1 becomes

$S_{t}=S_{o} e^{r}$

The second scenario is that with a multiplicative error with a varying mean value $\mu$ from 0.5 to 1.5 to provide an uncertainty of $50 \%$. However, a small random error with a small standard deviation of $r=0.1$ is maintained. By setting the standard deviation to $\sigma=0.1$, we suppose that the same systematic uncertainty in the term $M(\mu, \sigma)$ still has random variability. In both these error models, temperature is assumed to have a random gaussian error with a standard deviation of $1{ }^{\circ} \mathrm{C}$. However, when we consider the past, temperature estimates may have large errors. To evaluate the impact of these temperature errors on slope uncertainty, we performed a sensitivity analysis keeping almost constant the sulfate error, which had $\mathrm{M}=1$ and $r=0.1$, but the standard deviation for temperature varied from $0.5^{\circ} \mathrm{C}$ to $3{ }^{\circ} \mathrm{C}$. For each error model scenario we hypothesized, 10000 simulations were performed to obtain the average value and associated error bar of the slope that relates sulfate with temperature.

Figure 5 shows the result of the linear slope that relates sulfate and the temperature anomaly obtained by changing the value of the standard deviation $r$ of random errors describe in Equation 1. When the $r$ value is close to 0 , the expected cooling is still about $10^{-3}{ }^{\circ} \mathrm{C} / \mathrm{Tg}$, but when it increases to 0.5 , the expected cooling is only $7.5 \times 10^{-3}{ }^{\circ} \mathrm{C} / \mathrm{Tg}$. The error bar associated with each slope is about $0.5 \times 10^{-3}{ }^{\circ} \mathrm{C}$. Such variability demonstrates that even a small error in evaluating the amount of the sulfate mass can have an impact on the estimates of cooling. We noticed that the mean value 
of the slope does not depend on the mean sulfate error that is supposed to be zero, but only on the uncertainty of that error.

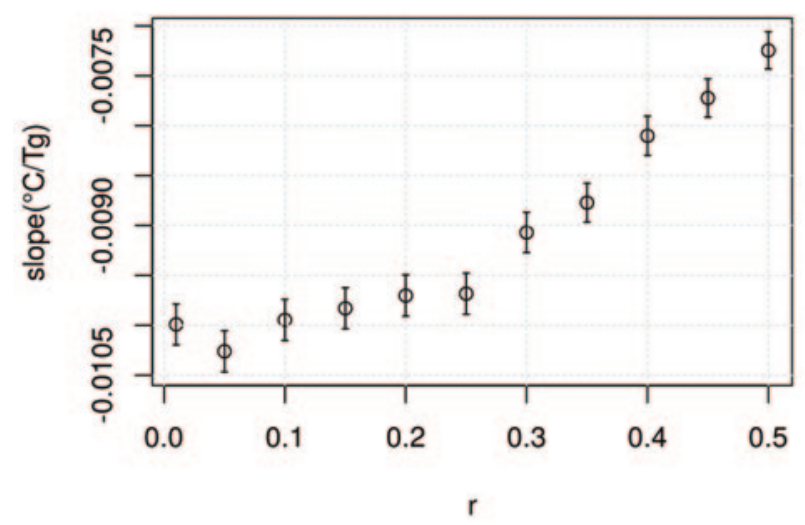

FIGURE 5. Relationship between sulfate and temperature as a function of exponent $r$ of Eq. 1, with $\mu=1$.

Sulfate measurement uncertainty can be related to an underestimation or overestimation of the method of estimation of sulfate from the ice cores. In such a case, the hypothesis is that there is a stochastic multiplicative term whose average goes from 0.5 , where the real sulfate would be half of that retrieved, to 2 , where the real sulfate would be underestimated by $50 \%$. The standard deviation value of this stochastic error is assumed to be small $(\sigma=0.1)$ compared to the mean value. The variability of the slope obtained in this manner demonstrates that if the sulfate emitted in past eruptions had been more than that retrieved by Gao et al. [2008] the cooling in terms of ${ }^{\circ} \mathrm{C} / \mathrm{Tg}$ would be reduced by up to $0.5^{\circ} \mathrm{C}$ for $100 \mathrm{Tg}$ of sulfate if the error

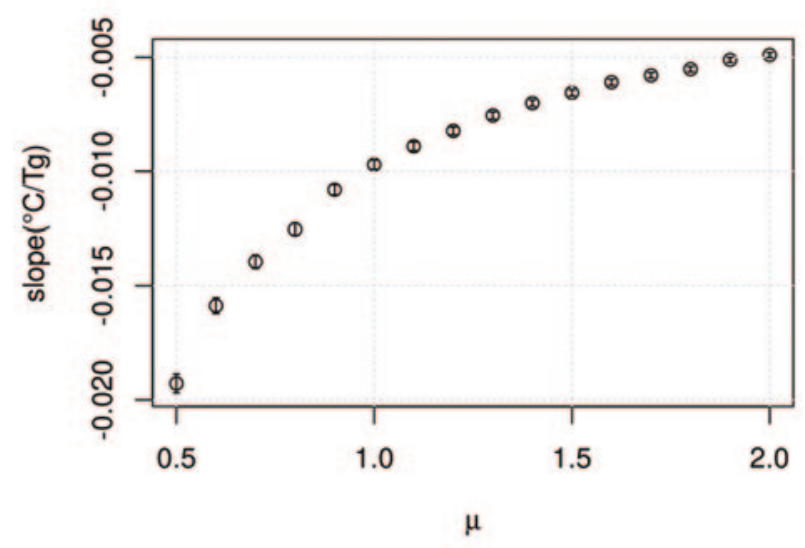

FIGURE 6. Relationship between sulfate and temperature as a function of the mean value $\mu$ of Eq. 1, keeping constant $r$. is $100 \%$ of the sulfate retrieved. On the other hand, a $100 \%$ overestimation of the measured sulfate would lead to cooler temperatures in Europe by up to $2^{\circ} \mathrm{C}$ per $100 \mathrm{Tg}$ of sulfate.

\subsection{TEMPERATURE UNCERTAINTIES}

One could object that the temperature anomaly error may also have an influence on the slope, changing the responses shown earlier. We first consider only an additive stochastic error on the temperature anomaly having a mean equal to zero with a specific standard deviation up to $3{ }^{\circ} \mathrm{C}$, which is a large value, as the absolute anomalies with respect to the moving average are less than $1{ }^{\circ} \mathrm{C}$. When we make a linear regression with only a stochastic temperature error, we obtain an error on the slope of $6 \times 10^{-4}{ }^{\circ} \mathrm{C} / \mathrm{Tg}$ (Figure 7).

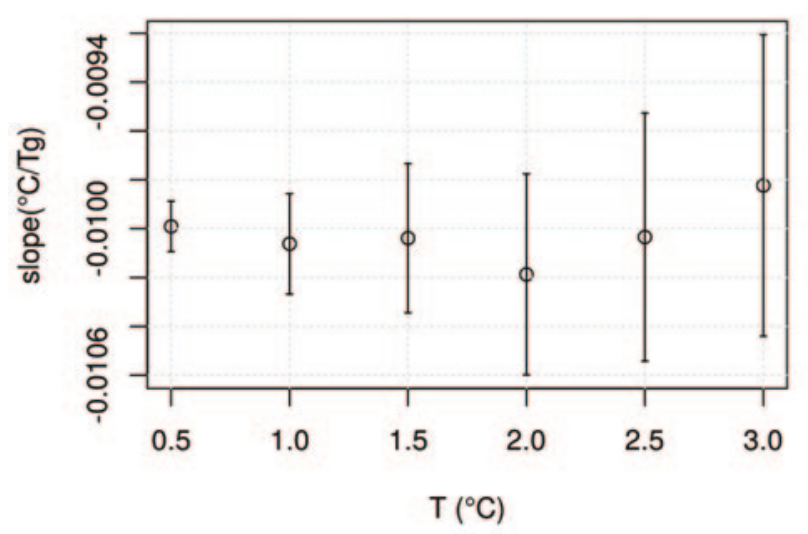

FIGURE 7. Relationship between sulfate and temperature as a function of an additive temperature error.

Even when we consider stochastic errors having a mean value different from zero, the mean and standard deviation of the slopes found by assuming a multiplicative error on sulfate and an additive error on temperature do not depend on the temperature anomaly error (see Figure 8). In short, we can say that the sulfate error has a larger impact with respect to the temperature anomaly error.

\section{DISCUSSION AND CONCLUSIONS}

Defining a relationship between stratospheric sulfate and changes to the surface temperature is a challenging task. Considerable uncertainty exists with measurements of aerosols injected into the atmosphere during volcanic eruptions. This is especially true with those from the pre-satellite era (before 1978). More- 


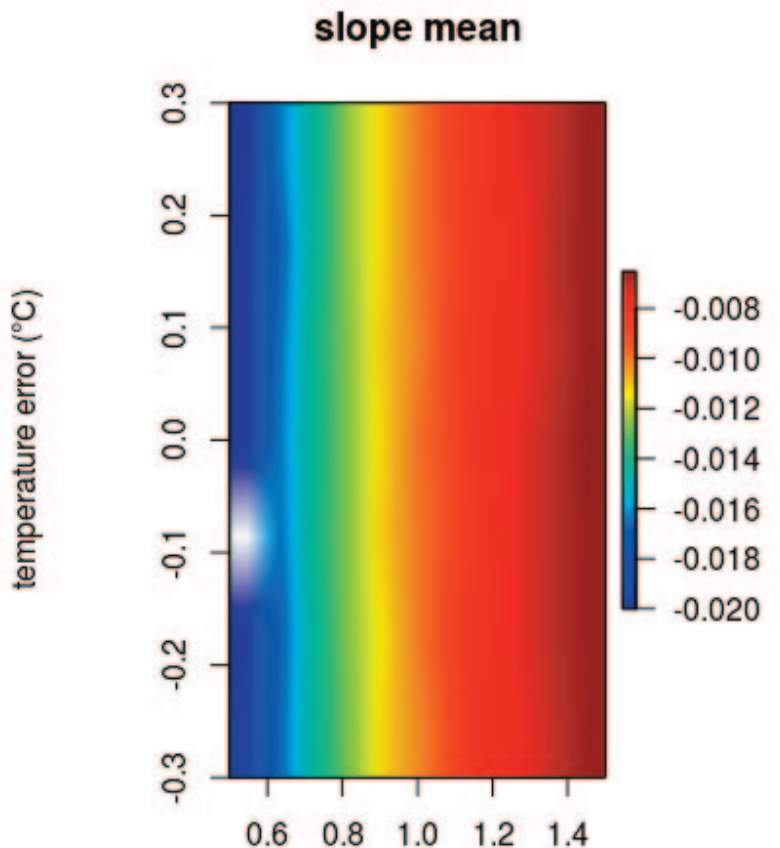

$\mu$

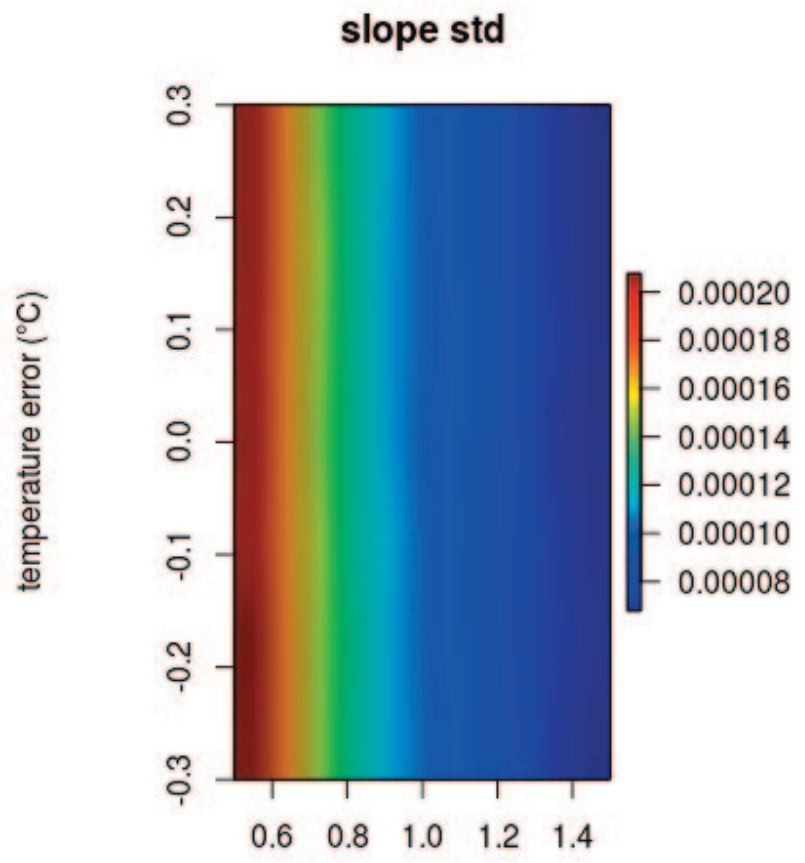

$\mu$

FIGURE 8. Relationship between sulfate and temperature as a function both of the error term $\mu$ and the temperature error.

over, the natural variability of climate can mask the impact of eruptions. As we have shown in our analysis, this is particularly true when the stratospheric sulfate emissions are limited to a few Tg. We propose a simple model using NH stratospheric sulfate aerosol loading to calculate the European temperature change following 22 large eruptions events using deposited sulfate measurements from ice cores and average annual temperature estimates for the European region. This empirical model is based on historical observations and takes the form of a linear regression. Large volcano eruptions are quite rare, and the data set we used contains only three events that were associated with sulfate mass larger than $40 \mathrm{Tg}$. These three events determined the significance of the slope of the linear regression we found. This slope of $-10 \times 10^{-3}{ }^{\circ} \mathrm{C} / \mathrm{Tg}$ was found with two different techniques: a simple regression with all the 22 events included and with a jackknife procedure, which also provides an estimate of possible errors. The slope is significant at 95\% following a Student's t-test and a non-parametric test. The correlation value, equal to 0.56 , between sulfate and average northern hemispheric temperature is also significant at 95\%. These results are in agreement with those found by Oliver [1976], who analyzed the response of temperature to volcanic dust rather than sulfate.
Earlier studies such as Sigurdsson [1990] and Devine et al. [1984], for instance, have found a power law relationship, but they considered only a few volcanic eruptions that led to negative variations of temperature. We questioned these studies, as the selection of only a few eruptions may have introduced selection and small sample bias.

With the power law found by Sigurdsson [1990] and the linear relationship that we found, we try to make a few predictions of temperature as a function of stratospheric sulfate mass, and we can see that the power law is a poor predictor for small eruptions and even for super-volcano eruptions. In fact, the change of temperature with an eruption injecting a small amount of sulfate mass (e.g., $10 \mathrm{Tg}$ ) is about $0.5^{\circ} \mathrm{C}$ cooler following a $1 / 3$ power law versus a change in the range of 0.1 ${ }^{\circ} \mathrm{C}$ given by the linear model that appears more appropriate. Only when the sulfate mass is in the range of $100 \mathrm{Tg}$ are the two models in agreement. However, studies performed by using climate models suggest that a super-eruption with $2000 \mathrm{Tg}$ of sulfate mass injected into the atmosphere, an unlikely but possible event, would cool the earth's surface by more than $10{ }^{\circ} \mathrm{C}$. Our linear model, with all the cautionary notes related to data extrapolation, gives a prediction of -18 ${ }^{\circ} \mathrm{C}$ for the European region. This result falls between 
the $-10^{\circ} \mathrm{C}$ of Jones et al. [2005] and the $-25^{\circ} \mathrm{C}$ of Harris [2008]. However, we should remember that such cooling effects could be less marked in some regions depending on where the eruption occurs.

In this paper, we tried to quantify the variability of the relationship obtained by a linear regression between European temperature anomalies and sulfate as retrieved from ice cores by adopting a Monte Carlo approach. As sulfate is a positive quantity, a multiplicative stochastic error model composed of two terms was used to define the sulfate. One term accounted for errors in the underestimation or overestimation of the sulfate, while the other, an exponential term, accounted for random errors. The former, as expected, had a large impact on slope variability, while the latter had a limited impact on the slope, but in general there was a reduction of the cooling estimate of about $3 \times 10^{-3}{ }^{\circ} \mathrm{C} / \mathrm{Tg}$. This result comes as a surprise, as the average value of the random error $r$ is 0 , whereas only the standard deviation changes in our experiments. The error on the temperature anomalies, instead, was expected to be additive with the anomalies both positive and negative. We found that the temperature error has no impact on the slope, suggesting that reducing errors on the sulfate will have an improvement on the relationship that relates volcanic sulfate to temperature. Our results, although limited to observation data, are consistent with the extremes and variability found in other studies with numerical models [Harris and Highwood, 2011; Meronen et al., 2012; Timmreck et al., 2012; Pausata et al., 2015].

Acknowledgements. Analysis reported in this paper was performed by using the language R. We wish to thank you the data provider IGBP PAGES/World Data Center for Paleoclimatology NOAA/NCDC Paleoclimatology Program, Boulder CO, USA for the European Seasonal Temperature Reconstructions and 1500 year ice core-based stratospheric volcanic sulfate data.

\section{REFERENCES}

Ammann, C.M. (2003). A monthly and latitudinally varying volcanic forcing dataset in simulations of 20th century climate, Geophys. Res. Lett., 30(12):1657, doi: 10.1029/2003GL016875.

Ammann, C. M., P. Naveau (2003). Statistical analysis of tropical explosive volcanism occurrences over the last 6 centuries, Geophys. Res. Lett., 30(5), 1210, doi: 10.1029/2002GL016388.
Arfeuille, F., D. Weisenstein, H. Mack, E. Rozanov, T. Peter, S. Brönnimann (2014). Volcanic Forcing for Climate Modeling: A New Microphysics-Based Data Set Covering Years 1600-present, Clim. Past, 10, 359-75, doi:10.5194/cp-10-359-2014.

Baillie, M.G.L., J. McAneney (2015). Tree ring effects and ice core acidities clarify the volcanic record of the first millennium, Clim. Past, 11, 105-114. doi:10.5194/cp-11-105-20155.

Baroni, M., J. Savarino, J. Cole-Dai, V.K. Rai, M.H. Thiemens (2008). Anomalous sulfur isotope compositions of volcanic sulfate over the last millennium in Antarctic ice cores, J. Geophys. Res., 113, D20112, doi:10.1029/2008JD010185.

Baskerville, G. L. (1972). Use of logarithmic regression in the estimation ofplant biomass, Can. J. For. Res., 2, 49-53, doi:10.1139/x72-009.

Bradley, R.S. (1988). The explosive volcanic eruption signal in northern hemisphere continental temperature records, Clim. Chang., 12, 221-243, doi:10.1007/BF00139431.

Bradley, R.S., P.D. Jones (1992). Records of explosive volcanic eruptions over the last 500 years. In Climate Since AD 1500 edited by Bradley and Jones 606-622.

Brandsdottir, B., W. Menke, P. Einarsson, R.S. White, R.K. Staples (1997). Faroe-Iceland Ridge

Experiment 2. Crustal structure of the Krafla central volcano, J. Geophys. Res., 102, 7867-7886.

Briffa, K.R., P.D. Jones, F.H. Schweingruber, T.J. Osborn (1998). Influence of volcanic eruptions on Northern Hemisphere summer temperature over the past 600 years, Nature, 393, 450-455.

Camuffo, D., S. Enzi (1995). Impact of the clouds of volcanic aerosols in Italy during the last 7 centuries, Natural Hazards, 11, 135-161.

Crowley, T.J., K.-Y. Kim, (1999). Modeling the temperature response to forced climate change over the last six centuries, Geophys. Res. Lett., 26, GL900347, 1901-1904.

Devine, J.D., H. Sigurdsson, A.N. Davis, S. Self (1984). Estimates of sulfur and chlorine yield to the atmosphere from volcanic eruptions and potential climatic effects, J. Geophys. Res., 89, 6309-6325.

Dunn, J. (2004). The influence of volcanic activity on large-scale atmospheric processes: A discussion, Weather, 59, 46-49, doi:10.1256/wea.14.03.

Esper, J., L. Schneider, P.J. Krusic, J. Luterbacher, U. Büntgen, M. Timonen, F. Sirocko, E. Zorita, (2013). European summer temperature response to annually dated volcanic eruptions over the past nine centuries, Bull. Volcanol., 75, 1-14. 
Feng, M., J. Whitford-Stark (1986). The 1719-1721 eruptions of potassium-rich lavas at Wudalianchi, China, J. Volcanol. Geotherm. Res, 30, 131 - 148.

Fischer, E. M., J. Luterbacher, E. Zorita, S. F. B. Tett, C. Casty, H. Wanner (2007). European climate response to tropical volcanic eruptions over the last half millennium, Geophys. Res. Lett., 34, L05707, doi:10.1029/2006GL027992.

Gao, C., A. Robock, C. Ammann (2008). Volcanic forcing of climate over the past 1500 years: an improved ice core-based index for climate models, J. Geophys. $\quad$ Res., 113, D23111, doi:10.1029/2008JD010239

Gautier, E., J. Savarino, J. Erbland, A. Lanciki, P. Possenti (2016) Variability of sulfate signal in ice core records based on five replicate cores, Clim. Past, 12, 103-113, https://doi.org/10.5194/cp-12-1032016.

Hansen, J., R. Ruedy, M. Sato, M. Imhoff, W. Lawrence, D. Easterling, T. Peterson, T. Karl (2001). A closer look at United States and global surface temperature change, J. Geophys. Res., 106, 947-963.

Harris, B. (2008). The potential impact of super-volcanic eruptions on the Earth's atmosphere, Weather, 63, 221-225.

Harris, B.M., E.J. Highwood (2011). A simple relationship between volcanic sulfate aerosol optical depth and surface temperature change simulated in an atmosphere-ocean general circulation model, J. Geophys. Res., Atmospheres 116, D05109.

Hegerl, G.C., T.J. Crowley, S.K. Baum, K.-Y. Kim, W.T. Hyde, (2003). Detection of volcanic, solar and greenhouse gas signals in paleo-reconstructions of Northern Hemispheric temperature, Geophys. Res. Lett., 30, 46-1.

Highwood, E.J., D.S. Stevenson (2003). Atmospheric impact of the 1783-1784 Laki Eruption: Part II Climatic effect of sulphate aerosol., Atmos. Chem. Phys., 3, 1177-1189.

Hofmann, D. (1987). Perturbations to the global atmosphere associated with the El Chichon volcanic eruption of 1982, Reviews of Geophysics, 25, 743759,1987

Jones, G.S., J.M. Gregory, P.A. Stott, S.F.B. Tett, R.B. Thorpe (2005). An AOGCM simulation of the climate response to a volcanic super-eruption, Clim. Dynam., 25, 725-738.

Langmann, B. (2014). On the role of climate forcing by volcanic sulphate and volcanic ash, Advances in Meteorology, ID340123,

17 , doi:10.1155/2014/340123.
Lough, J.M., Fritts, H.C. (1987). An assessment of the possible effects of volcanic eruptions on North American climate using tree-ring data, 1602 to 1900 A.D. Clim. Chang. 10, 219-239.

Luterbacher, J., D. Dietrich, E. Xoplaki, M. Grosjean, H. Wanner (2004). European seasonal and annual temperature variability, trends and extremes since 1500, Science, 303, 1499-1503.

Mass, C.F., D.A. Portman (1989). Major volcanic eruptions and climate: a critical evaluation, J. Climate, 2, 566-593.

Merlis, T. M., I. M. Held, G. L. Stenchikov, F. Zeng, L. W. Horowitz (2014). Constraining transient climate sensitivity using coupled climate model simulations of volcanic eruptions, J. Clim., 27, 7781-7795.

McCormick, M.P., L.W. Thomason, C.R. Trepte (1995). Atmospheric effects of the Mt. Pinatubo eruption, Nature, 373, 399-404.

Meronen, H., S.V. Henriksson, P. Räisänen, A. Laaksonen (2012). Climate effects of northern hemisphere volcanic eruptions in an Earth System, Model. Atmos. Res., 114, 107-118.

Mitchell, T., P.D. Jones (2005). An improved method of constructing a database of monthly climate observations and associated high-resolution grids, Inter. J. Climat., 25, 693-712.

Oliver, R.C. (1976). On the response of hemispheric mean temperature to stratospheric dust: An empirical approach, J. Appl. Meteor., 15, 933-950.

Pausata, F. S. R., A. Grini, R. Caballero, A. Hannachi, $\varnothing$. Seland (2015). High-latitude volcanic eruptions in the Norwegian Earth System Model: the effect of different initial conditions and of the ensemble size, Tellus B, 67, 26728.

Pioli, L., E. Erlund, E. Johnson, K. Cashman, P. Wallace, M. Rosi, H. Delgado Granados (2008). Explosive dynamics of violent strombolian eruptions: the eruption of Parícutin volcano 1943-1952 (Mexico), Earth Planet. Sci. Lett., 271, 359-368.

Plummer, F. G. (1898). Reported volcanic eruptions in Alaska, Puget Sound, etc., 1690-1896: in Holden, E. S., (ed.). A Catalogue of Earthquakes on the Pacific Coast 1769-1897, Smithsonian Institution Miscellaneous Collections 1087, City of Washington D.C., Smithsonian Institution, 24-27.

R Development Core Team (2008). R: A language and environment forstatistical computing. R Foundation for Statistical Computing, Vienna, Austria. ISBN 3-900051-07-0, http://www.R-project.org.

Rampino, M.R., S. Self (1984). Sulphur-rich volcanic eruptions and stratospheric aerosols, Nature, 310, 677-679, doi:10.1038/310677a0. 
Robock, A. (2000.) Volcanic eruptions and climate, Rev. Geophys., 38, 191-219.

Robock, A., J. Mao (1992). Winter warming from large volcanic eruptions, Geophys. Res. Lett., 19, 24052408.

Robock, A., J. Mao (1995). The volcanic signal in surface temperature observations, J. Clim., 8, 1086-1103.

Rosi, M., C. Principe, R. Vecci (1993). The 1631 eruption of Vesuvius reconstructed from the review of chronicles and study of deposits, J. Volcanol. Geotherm. Res., 58, 151-182.

Sadler, J.P., J.P. Grattan (1999). Volcanoes as agents of past environmental change, Glob. Planet. Chang. 21, 181-196.

Scaillet, B., J.F. Luhr, M.R. Carroll (2003). Petrological and volcanological constraints on volcanic sulfur emissions to the atmosphere, in Volcanism and the Earth's Atmosphere, Geophys. Monogr. Ser., 139, edited by A. Robock and C. Oppenheimer, 11-40, AGU, Washington D. C.

Sear, C.B., P.M. Kelly, P.D. Jones, C.M. Goodess (1987). Global Surface-Temperature Responses to Major Volcanic Eruptions, Nature, 330, 365-67, doi:10.1038/330365a0.

Self, S., M.R. Rampino, M.S. Newton, J.A. Wolff (1984). Volcanological study of the great Tambora eruption of 1815, Geology, 12, 659-663.

Shindell, D.T., G.A. Schmidt, M.E. Mann G. and Faluvegi (2004). Dynamic winter climate response to large tropical volcanic eruptions since 1600, J. Geophys. Res., 109, D05104, doi:10.1029/2003JD004151.

Sigurdsson, H. (1990). Evidence of volcanic loading of the atmosphere and climate response. Glob. Planet. Chang. 3, 277-289.

Swingedouw, D., J. Mignot, P. Ortega, M. Khodri, M. Menegoz, C. Cassou, V. Hanquiez, (2017). Impact of explosive volcanic eruptions on the main climate variability modes, Glob. Planet. Chang., 150, 24-45.

Tamburello, G., E. P. Kantzas, A. J. S. McGonigle, A. Aiuppa (2011). Vulcamera: A program for measuring volcanic SO 2 using UV cameras, Ann. Geophys., 54, 2, doi:10.4401/ag-5181.

Tartaglione, N., (2010). Relationship between precipitation forecast errors and skill scores of dichotomous forecasts, Wea. Forecasting, 25, 355-365, doi:10.1175/2009WAF2222211.1.

Textor, C., H.F. Graf, A. Longo, A. Neri, T. Esposti Ongaro, P. Papale, C. Timmreck, G.G.J. Ernst (2005). Numerical simulation of explosive volcanic eruptions from the conduit flow to global atmospheric scales, Ann. Geophys., 48, 817-842.
Tian, Y., J.G. Huffman, F.R. Adler, L. Tang, M. Sapiano, V. Maggioni, H. Wu (2013) Modeling errors in daily precipitation measurements: additive or multiplicative?, Geophys. Res. Lett. 40, 2060-2065, doi: $10.1002 /$ grl.50320

Timmreck, C. (2012). Modeling the climatic effects of large explosive volcanic eruptions. Wiley Interdisciplinary Reviews: Climate Change 3, 545-564, doi: 10.1002/wcc.192

Timmreck, C., H.-F Graf, D. Zanchettin, S. Hagemann, T. Kleinen, K. Krüger (2012). Climate response to the Toba super-eruption: Regional changes, Quat. Int., 258, 30-44, doi: 10.1016/j.quaint.2011.10.008

Timmreck, C., S.J. Lorenz, T.J. Crowley, S. Kinne, T.J Raddatz, M.A. Thomas, J.H. Jungclaus (2009). Limited temperature response to the very large AD 1258 volcanic eruption, Geophys. Res. Lett., 36, L21708, doi: 10.1029/2009GL040083.

Toon, O.B., J.B. Pollack (1980). Atmospheric aerosols and climate, American Scientist, 68, 268-278.

Washington, H.S. (1926). Santorini eruptions of 1925 , Bull. Geol. Soc. Am., 37, 349-384.

Witham, C.S., C. Oppenheimer (2004). Mortality in England during the 1783-4 Laki Craters eruption, Bull. Volcanol., 67, 15-26.

Wunderlich, F., D.M. Mitchell (2017). Revisiting the observed surface climate response to large volcanic eruptions, Atmos. Chem. Phys., 17, 485-499, doi: 10.5194/acp-17-485-2017.

Xoplaki E., J. Luterbacher, H. Paeth, D. Dietrich, N. Steiner, M. Grosjean, H. Wanner (2005). European spring and autumn temperature variability and change of extremes over the last half millennium, Geophys. Res. Lett., 32: L15713.

Zielinski G.A., R.J. Fiacco, P.A. Mayewski, L.D. Meeker, S. Whitlow, M.S. Twickler, M.S. Germani K. Endo, M. Yasui (1994). Climatic impact of the A.D. 1783 Asama (Japan) eruption was minimal: evidence from the GISP2 ice core, Geophys. Res. Lett., 21, 2365-2368.

"CORRESPONDING AUTHOR: Nazario TARTAGLIONE, NORCE Norwegian Research Centre,

Bjerknes Centre for Climate Research, Bergen, Norway; email: nazario.tartaglione@norceresearch.no

(C) 2019 the Istituto Nazionale di Geofisica e Vulcanologia. All rights reserved 